\title{
A Critical Analysis of the Discourse of Doctor-Patient Interaction: A Case Study
}

\author{
Mosisa Asegid Takele \\ College of Social Sciences and Humanities \\ Mekdela Amba University \\ Mekane Selam, Ethiopia \\ mossasegid@gmail.com
}

\begin{abstract}
The study undertook a critical analysis of the discourse of doctor-patient interaction under the ENT (Ear, Nose, and Throat) clinic of Gondar Hospital, which is found in the Amhara regional state of Ethiopia. Specifically, the study investigated the recurrent interactional features in the doctor-patient interactions, the manifestations of power relations through language use, as well as the ideological assumptions which are held by doctors and patients. To achieve these objectives, qualitative methods were used during data collection and analysis. Purposeful sampling was used to select the clinic where the study took place. Data were gathered through audio-recording and field notes. Before analysis, the audio recordings were transcribed using Jeffersonian Transcription conventions and then translated into English. The translated data were analyzed thoroughly using Fairclough's (1992) three-dimensional model of Critical Discourse Analysis. The study, thus, showed that interpersonal relationships between discourse interactants could be an indicative of their
\end{abstract}


social and power relations. Therefore, institutional discourse, specially, that of doctor-patient, could be a place for power struggle.

Keywords: Doctor-Patient Discourse, Critical Discourse Analysis, Fairclough's 3D Model

\section{Background of the Study}

Good health is a priceless asset to human beings; and the prominent role that communication plays has pushed effective medical interaction to a new level of importance. Subsequently, Fairclough (1992. p. 143) suggested, "The main arena for medical interaction can be most comprehensively viewed in terms of the doctor-patient relationship." The relationship between patients and doctors provides the foundations for establishing trust, rapport, and understanding, explaining diagnoses, and negotiating treatment; hence, the ways doctors and patients use language to transfer their messages determine how the patient's problem is understood, as well as shaping the relationship, which can have a healing value in its own right.

Nevertheless, even though the abovementioned and other renowned scholars suggested that the interaction between doctors and patients in the health care setting is the main ingredient for therapeutic results, many researches are still showing that there is a problem regarding the interaction between doctors and patients. The main reason for this problem is that, as Beran (1999, p 23) stated, "[doctor-patient] interaction is different from ordinary or everyday spoken interaction because it takes place within an institutionalized setting. These institutions (such as health care institutions) can shape all forms of discourse, 
which in turn, are shaped by wider power relations. This study thus systematically explored the often-opaque relationships of causality and determination between doctors and patients, and investigated how such practices arise out of and are ideologically shaped by relations of power and struggles over power.

\section{Theoretical Basis of the Study}

\subsection{Discourse Analysis}

At the heart of applied linguistics in general and critical discourse analysis in particular is the notion of discourse. Much has been said on discourse in different literature. At the early stages of linguistics, Ferdinand De Saussure made his remarks regarding language in his work on langue and parole (Fairclough, 1989). As Fairclough (1989) noted, Saussurian views were concerned with language as a system (langue) which is uniform for all members of a speech community but viewed language use as an individually determined practice (parole). But this view that language use is determined by individual's preferences is limited because contemporary sociolinguistics has shown that variation in language use is not directly related to individual's choices but to the social relations in which the language is used, i.e. the social setting, the social identities and the social purpose (Fairclough, 1998),

Later on, however, as the functionalist approach to linguistics became prominent, discourse was defined as any sort of language use (Schiffrin, 2001). This view has been mostly accepted by critical discourse analysts. As Schiffrin (2001) noted, this view does not emphasize on the mere structure of language, as Saussure did, but goes further to the function that language serves in various social contexts. 
Finally, when studies in discourse analysis became prominent, the conceptualization of discourse transformed dramatically. In this regard, Fairclough (1989) uses the term discourse to refer to the whole process of social interaction. Any social interaction that involves language can thus be considered as discourse in this view. For instance, a medical consultation is the just a product of the social interaction between patients and doctors.

\subsection{Critical Discourse Analysis}

Critical discourse analysis is the major theoretical and methodological framework based on the principles of which this study was conducted. CDA is a multidisciplinary approach to the analysis of texts with focus on their social roles in relation to domination and social inequality. However, to achieve its aims, CDA draws various theories from other fields. As Chouliaraki \& Fairclough (1999) noted, CDA brings a variety of theories into play for its undertaking. First, it needs social theories for the conceptualisation of discourse and the social world. Second, it needs a linguistic theory for understanding the linguistic aspects of the social phenomenon under study.

According to Fairclough (2003), in the investigation of a certain text, the researcher cannot randomly apply pre-existing theoretical frameworks because the selection of theories depends upon the perspective from which the researcher is attempting to investigate the text. Three points need to be considered in the selection of theories and methods for CDA. First, the social issues that the study focuses on. Based on the issues to be studied, the researcher then adopts a social theory from which the issue can be best understood. Having decided that, a discourse perspective is required because the researcher needs a particular viewpoint from 
which the discursive aspects of the issue can be well understood. Finally, a linguistic theory to investigate the textual aspects of the issue is required. Accordingly, in this study, the three-dimensional framework adapted by Fairclough is used.

In the study of CDA, Fairclough makes a distinction between discourse and text. Fairclough (1992, p. 3) asserts that 'text' is used for both written texts and transcripts of spoken interaction and a text is regarded as a product of the text production process; while 'discourse' refers to the use of language seen as a form of social practice, which underlies a dialectical relationship between the microstructure of discourse like linguistic structures such as different interactional features and the macrostructures of society such as social structure, ideology, and power. Fairclough (1992, p. 71) states that "Discourse refers to the whole process of social interaction, of which text is just a part".

According to Fairclough (1992), a communicative event has three dimensions: a social dimension, a discursive dimension and. a textual dimension. Thus, the aim of the three-dimensional approach is to map three separate forms of analysis onto one another: analysis of (spoken or written) language texts, analysis of discourse practice (processes of text production, distribution and consumption) and analysis of discursive events as instances of sociocultural practice. Fairclough expresses this visually with a three-dimensional model.

\section{Data Analysis}

In line with the analytical framework that has been introduced in the previous section, this segment of the article presents analysis of the data. The main focus of this study is to critically analyze the discourse of doctor-patient interaction. In order to do so, five interactions between doctors and patients were selected from the transcribed texts. 
Additionally, the data from the field notes of the researcher has been included. Once the audio data is transcribed using Jeffersonian Transcription System (Jefferson, 2004). Similar patterns were observed in the transcription. However, generally, there were three systematic recurrences of certain expressions that indicate the manifestation of power relations between the doctors and the patients. These manifestations will be discussed in different sub-headings below.

\subsection{Asymmetrical Turn Allocation}

Extracts from the corpus data has shown the doctors' dominant role in allocating turns throughout their interaction with patients. In this regard, Fairclough (1992, p. 234) presents some questions as a framework for the analysis of turn taking process in an interactional setting. These set of questions are: "What turn taking rules are in operation? Are the rights and obligations of participants (with respect to overlap or silence, for example) symmetrical or asymmetrical?" I used these questions as a guideline to analyze the process of turn-taking and the distribution of turns in the doctor-patient interactions.

The notion of turn-taking implies a participant getting chance to speak. Unless the participant takes turns in a regular pattern, the outcome can be asymmetrical interaction, because "interaction is organized around turns of talk that are delicately meshed together" (Liddicoat, 2007, p. 41). Thus, turn-taking and the distribution of turns between participants can influence the nature of the interaction.

In this regard, a profound examination of the audio recorded data depicts that the doctors can be seen as the only interlocutors having the role of allocating turns throughout the 
interactions. This can be seen in the following extract:

\section{Extract 1}

\section{$\underline{\text { Amharic Version }}$}

Turn

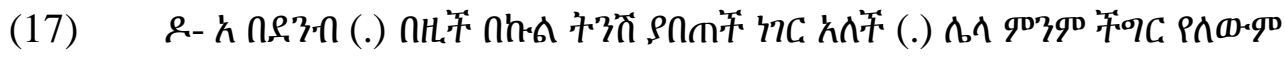

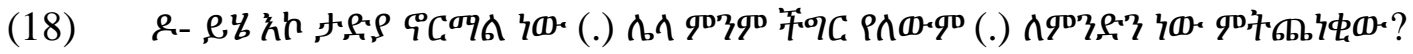

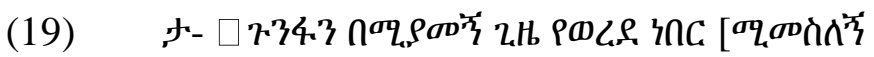

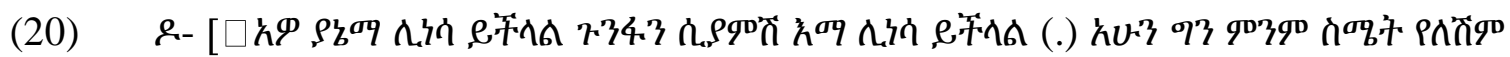
h.SQS?

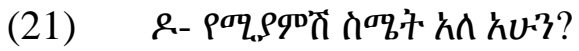

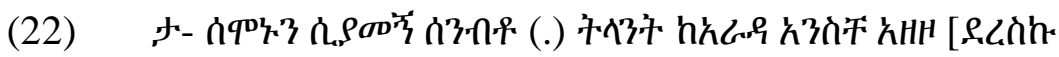

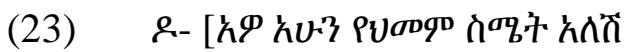

\section{$\underline{\text { English Version }}$}

$\underline{\text { Turn }}$

(17) D- 'HA' wider (.) there is a bit swollen thing on this side (.) besides that, there is nothing wrong with it (.)

(18) D- This is normal (.) there is no other problem (.) why are you worried?

(19) P-While I was having a cold (.) I felt like it has come [down

(20) D- Yes it is possible when you're having a cold (.) it's possible (.) but you don't have

any feelings now, do you 


$$
\text { D- Are you experiencing any sickness right now? }
$$

P- I have been feeling sick lately (.) yesterday I traveled from arada to azezo

$$
\text { D- yes (.) are you experiencing any pain right now? }
$$

The above interaction shows the dominant role of the doctor in the allocation of turns. As we can see from the above extract, the doctor self-selects himself to take the floor on 'turn 18'. This happened because, even though the doctor has finished what he has got to say on 'turn 17', the patient did not show interest to take the floor. Consequently, Schiffrin et al. (2001, p. 65) state "If no other speaker self-selects to take the role, the current speaker may then continue to talk again". Therefore, the doctor self-selects himself to take the floor, and invited the patient to take the floor by asking her a question. Hence, the patient on 'turn 19' accepts the invitation and replied accordingly. By addressing a question to the patient, the doctor chooses her as the next floor taker. This shows an obvious exercise of control by the doctor.

In the extract, both the doctor and the patient take turns to talk about one topic. However, most of the turns were dominated by the doctor's contribution. The doctor not only have longer and higher number of turns, but also is the one who is allocating the floor by asking the patient a question. This provides evidence that in the interaction, the distribution of turns is asymmetrical.

This is not the only evidence that contribute to the interaction being asymmetrical. The turn-taking system in the above extract is also influenced by interruptions from the doctor. As we can see from 'turn 20 and turn 23' of the Amharic version of the data, the doctor interrupted the patient before she finishes her turn. Hence, Drew and Heritage (1998, p. 
10) identified interruptions as "A power device imposed on the 'interruptee' by the interrupter". Thus, this perspective can indicate the doctor's interruption as an interactional application of power over the patient.

3.2 Doctors' Controlling of the Overall Structural Organization of the Interactions

Throughout the corpus data, it appears that the interactions are mainly organized around questions from the doctors. Questions, in this case, can be seen as a part of question-answer adjacency pairs. Adjacency pairs, according to Schiffrin et al. (2001, p, 68) are "Pairs which consists of a first pair and a second pair and produced by different speakers within the interaction". However, since the concept of adjacency pairs are usually analyzed by conversation analysis, which have a different methodological procedure than CDA, the structural organization of the doctor-patient interaction here is analyzed using Exchange Structure. According to Fairclough (1992, p. 234), in order to analyze the structural organization of an interaction, the investigator has to ask "what exchange structure is in operation?" Thus, I have employed this question so as to analyze the structural organization of the interactions.

In this regard, the extracts chosen for analysis have shown that the doctors are the ones who initiate an exchange. They usually do this by asking questions. This can be seen from the following extract: 
Extract 2

\section{$\underline{\text { Amharic Version }}$}

Turn

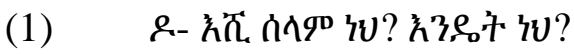

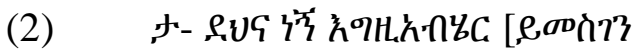

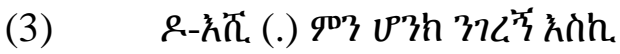

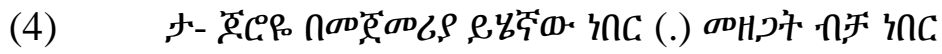

\section{$\underline{\text { English Version }}$}

$\underline{\text { Turn }}$

(1) D- Ok how are you? Are you fine?

(2) P- I am fine thanks to God

(3) D- Ok (.) What's wrong with you? (.) Tell me

(4) P- My ear um at first it was this one (.) it was only an obstruction

In 'turn 1' the doctor initiates an exchange by asking the patient, which is presented in the extract as a form of a greeting, which shows the social function of language use. The patient in 'turn 2' then give a response for the doctor's question. Thus, in 'turn 3' the doctor explicitly acknowledges the patient's response by uttering the word 'ok' and moving onto the next course of the consultation, which shows the completion of the first cycle of the interaction.

Additionally, 'turn 1 and 2' represents the first part of question-answer adjacency pair. Because, the doctor (turn 1) starts the interaction by asking a question. In addition to this, when the doctor finishes addressing his question, the patient in turn 2 starts answering the 
question that was raised by the doctor in turn 1 .

Furthermore, we can also find the same exchange structures in the following extracts:

\section{Extract 3}

\section{$\underline{\text { Amharic Version }}$}

$\underline{\text { Turn }}$

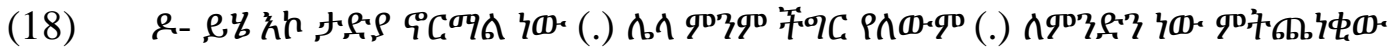

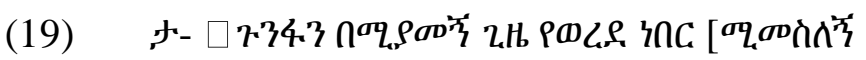

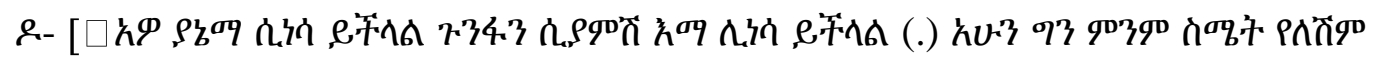

h.QA?

\section{$\underline{\text { English Version }}$}

$\underline{\text { Turn }}$

(18) D- This is normal (.) there is no other problem (.) why are you worried?

(19) P- $\square$ While I was having a cold (.) I felt like it has come [down

(20) D- $\square$ Yes it is possible when you're having a cough (.) it's possible (.) but you don't

have any feelings now, right?

As it can be seen from the extract, the interaction is organized around questions from the doctor, which subsequently are answered by the patient. For instance, in 'turn 18', the doctor initiated an exchange by asking the patient 'why are you worried', which is answered by the patient (turn 19) by telling the doctor the reason why she is concerned. Subsequently, the doctor (turn 20) acknowledges her response explicitly when he told her 'yes, it's possible 
when you're having cold.

Thus, from the above analysis, it can be understood that the exchange structure of the interactions has an initiation from the doctor, a response from the patient, and then an acknowledgment and a follow up question. This repeated one-sided initiation of requests for information by the doctor causes asymmetrical interaction. Furthermore, it seems that through their questions, the doctors are the ones who control the interaction in terms of exchange structure. No matter questions are understood as parts of adjacency pairs or exchange structure, it is the doctors who initiate the basic unit of the interaction, and to a large extent determine its characters. Through their questions they seem to limit the patients in terms of what they can say. Thus, these repeated questions that the doctors ask throughout the interactions are indeed an important index of interactional control since to ask question is to claim power over emerging talk.

\subsection{Dominance through Topic Control}

Another recurrent theme in the corpus data is the dominant control of the topic by the doctors. According to Fairclough (1992, p. 234), in order to analyze topic control in interactional settings, the analyst asks: "how are topics introduced, developed, and established and by whom? Does one participant evaluate the utterance of others?" I used these sets of questions as a framework to analyze how the various topics are introduced in the doctor-patient interactions.

In this regard, in their interaction with patients, only the doctors were in situation to determine the nature and purpose of the interaction at the beginning and/or to prevent the 
patient's contributions that they believe are not relevant for the medical consultations. We can see this from the following extract:

\section{Extract 4}

\section{Amharic Version}

$\underline{\text { Turn }}$

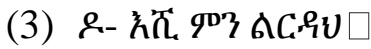

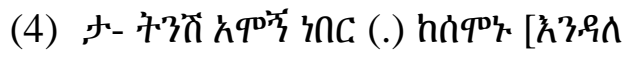

(5) R- [

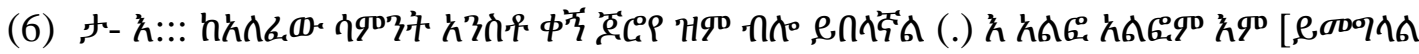

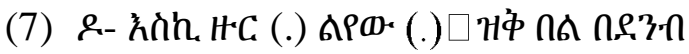

\section{English Version}

$\underline{\text { Turn }}$

(3) D- ok what can I help you?

(4) P- I am a little bit sick (.) lately

(5) D- Where do you feel the pain?

(6) P- um since last week my right ear is itchy (.) besides, sometime it exudates

(7) D- Turn around (.) let me see it (.) $\square$ lower your head further

As it can be seen from the extract (turn $3 \& 5$ ), topics are introduced by the doctor using questions as his tool. By doing that, the doctor is the one who decide what they should be talking about. In this regard, the doctor mostly uses interrogative sentences about a specific topic after which the patient is expected to take his turn and reply accordingly. This can be 
shown in 'turn 3', when the doctor shifts from greeting the patient to attempting to discover the reason for his attendance using a question. Additionally, in turn 7 the doctor shifts from conducting a verbal and/or physical examination to further investigating the patient's illness.

Furthermore, it can be seen from the excerpt that when the doctor offers a topic (turn 3), the patient accepts it and talks along (turn $4 \& 6$ ), and the doctor again goes on to develop and/or ask for elaboration (Turn $5 \& 7$ ). Thus, since the doctor is the only interlocutor who offers topics and decide what they should be talking about, an asymmetry can be observed in the take up of topics during the interaction.

Thus, from the above analysis, it can be deducted that the doctors are working through a pre-set agenda, because they were shifting from one phase of the interaction to another, once they have what they believe as enough information. Moreover, it is clearly seen from the extracts that the doctors are the one who organize and control the topic of the interaction. They mainly accomplish this through questions and interruptions. The doctors introduce, develop and dissolve topics using questions, and interruptions. Throughout the data, the doctors are the only interlocutors who are initiating every interaction.

In addition to this, as I have observed and jotted down, during the field note sessions of the study, the doctors were usually exercising their power over patients by performing directive speech acts without using any redressive strategies. For instance, the following directive speech acts were performed by the doctors:

Tell the next patients to not spit on the floor and to not hold their shoes against the wall!)

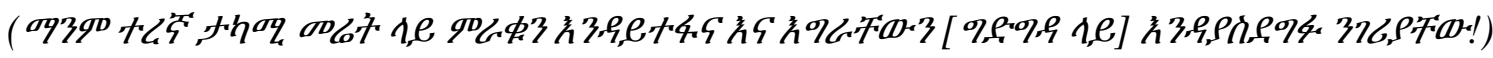

The doctor performed the above-mentioned directive speech act over a patient who 
was just leaving a room after attending a consultation with the doctor.

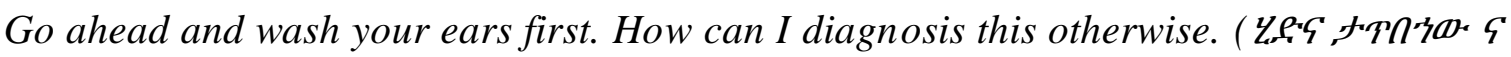

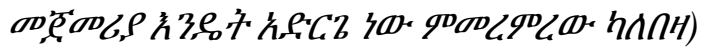

The above directive speech act does not only show how the doctor gives an order to the patient, but also how the patient's face needs were not maintained, or threatened. It can be seen from the extract that the doctor has not used any polite behavior towards the patient, and thus modify his utterances during the interaction. As I observed in the case of the above extract, the patient's ears were exuding pus, which is a potentially embarrassing situation for him. However, the doctor has not employed any preventive politeness strategies to avoid the face threatening and awkward incidents the patient might be facing at that moment.

Go outside and wait there, the nurse will bring it for you. The room is too hot already,

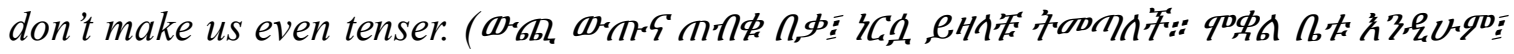

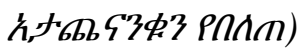

The doctor performed such Face Threatening Act on the patients, while they were waiting for the nurse to write drug prescriptions for them. In the above observation extracts, the doctors performed the directive speech acts without using any politeness strategies. As a result, they were the ones who threaten the face needs of the patients by performing speech acts without seeking to minimize the threats. Hence, According Culpeper (2011, p. 86) "bald-on-record Face Threatening Acts, is not considered to be impolite when the speaker is of a higher social status than the addressee".

On the contrary, the patients were careful not to threaten the doctors' face needs. Additionally, as I observed and noted down, the patients were performing and giving answers 
to the orders and requests of the doctors by doing what they were told. This clearly shows power asymmetry in the interactions. Consequently, as Fairclough (1992, p. 165) states "Politeness is based upon recognition of differences of power, degrees of social power, and so forth oriented to reproduce them without change".

In addition to this, I have witnessed and held field notes as to how the doctors were the only ones who were speaking with a high pitch range and confidence. Patients, on the other hand, were speaking with a very low intonation, which sometimes made it hard even for me during the transcription stage of the study to easily understand what they actually were saying. In this regard, the loudness may indicate confidence and authority of the doctors, whereas the soft or low intonation indicates uncertainty and politeness of the patients.

\section{Conclusion}

This section provides a brief summary of the conclusion drawn from the analysis in the previous section. In this regard, the analysis has shown that the manifestations of power through language use are attributed to three major things. Firstly, the analysis demonstrates how the doctor, using a number of discursive strategies, dominates the medical encounter, and restricting the conversational resources of the patient in order to follow to a pre-determined medical agenda. The doctors' authority is manifested through interactional features such as turn allocation and repeated interruptions, initiating every exchange by asking questions, and controlling the topic and setting the agenda of the interaction, and performing face threatening acts. Thus, these abovementioned discursive strategies collectively evince a clear degree of interactional control. Hence, it can be concluded that the 
doctors were the dominant interlocutors throughout the interactions. 


\section{References}

Beran, J. (1999). Doctor-Patient Communication: Part I- Introduction. Prague, Czech Republic: Karolinum .

Chouliaraki, L., \& Fairclough, N. (1999). Discourse in Late Modernity: Rethinking Critical Discourse Analysis. Edinburgh: Edinburgh University Press.

Culpeper, J. (2011). Towards an Anatomy of Politeness. The Journal of Pragmatics, 25-31.

Drew, K., \& Heritage, J. (1998). Conversational Analysis and Institutional Talk. In H. J. Cmejrkova. S, \& J. Svelta, Dialog Analysis (pp. 3-17). Tubingen: Niemeyer.

Fairclough, N. (1989). Language and Power. London: Longman.

Fairclough, N. (1992). Discourse and Social Change. Cambridge: Polity.

Fairclough, N. (1998). Discourse and Social Change. Cambridge: Polity Press.

Fairclough, N. (2003). Analyzing Discourse. London and New York: Routledge.

Jefferson, G. (2004). Glossary of Transcript Symbols with an Introduction. In G. Lerner, Conversation Analysis: Studies from the first generation (pp. 13-31). Amsterdam: John Benjamins.

Liddicoat, N. (2007). An Introduction to Conversational Analysis. London: Sage Publication Ltd.

Schiffrin, \& et'al. (2001). Handbook of Discourse Analysis. Oxford: Blackwell. 